\title{
Üretim Sistemlerinde Makine Öğrenmesi ile Kestirimci Bakım Uygulaması ve Modellemesi
}

\author{
Hakan Ceyhan $^{1 *}$, Mustafa Cem Kasapbaş ${ }^{2}$ \\ 1* İstanbul Ticaret Üniversitesi, Mühendislik Fakültesi, Bilgisayar Mühendisliği Bölümü, İstanbul, Türkiye, (ORCID: 0000-0003-1776-4827), \\ hakanceyhan83@gmail.com \\ ${ }^{2}$ İstanbul Ticaret Üniversitesi, Mühendislik Fakültesi, Bilgisayar Mühendisliği Bölümü, İstanbul, Türkiye, (ORCID: 0000-0001-6444-6659), \\ mckasapbasi@ticaret.edu.tr
}

(İlk Geliş Tarihi 5 Kasım 2021 ve Kabul Tarihi 3 Ocak 2021)

(DOI: 10.31590/ejosat.1019210)

ATIF/REFERENCE: Ceyhan, H., Kasapbaşı, M. C. (2022). Üretim Sistemlerinde Makine Öğrenmesi ile Kestirimci Bakım Uygulaması ve Modellemesi. Avrupa Bilim ve Teknoloji Dergisi, (33), 167-175.

$\ddot{O} \mathbf{z}$

Üretim sistemlerinin verimlilikleri söz konusu olduğunda bakım yaklaşımları son derece önemli bir role sahiptir. Geleneksel bakım yaklaşımları kısıtlı bir başarı sağlamış olsa da günümüz endüstriyel teknolojilerinin özellikle de Endüstri 4.0'ํn itici gücü ile birlikte makinelerden belirli standartlar ile veriler gerçek zamanlı okunabilmekte ve bu verilerle makine öğrenmesi (Machine Learning - MÖ) aracılığı ile bakım zamanları optimize edilebilmektedir. Böylece kestirimci bakım anlayışı ile üretim sürecindeki herhangi bir bakım gerektiren arıza önceden öngörülerek bu durum yaşanmadan önüne geçilebilmektedir. Bu çalışmada döküm fabrikasındaki makinede, makine öğrenmesi ile kestirimci bakım uygulamasını gerçekleştirebilmek amacıyla veriler 6 ay boyunca toplanmıştır. Elde edilen veriler ile temel bileşen analizi (Principal Component Analysis - TBA) ve rastgele orman (Random Forest - RO) makine öğrenmesi yöntemleri kullanılarak, sırasıyla denetimsiz ve denetimli olarak bakım zaman tahminleri $\% 85,17$ başarı oranı ile gerçekleştirilmiştir.

\section{Predictive Maintenance Application and Modeling With Machine Learning In Production Systems}

\begin{abstract}
Maintenance approaches have an extremely important role when it comes to efficiency in production systems. Although traditional maintenance approaches have had limited success, with the driving force of today's industrial technologies, especially Industry 4.0, all maintenance data generated on production machines can be collected in real time, and maintenance times can be optimized through machine learning. Thus, with the predictive maintenance approach, any maintenance-required breakdown in the production process can be foreseen and prevented before this situation occurs. In this study, data were collected for 6 months in order to implement predictive maintenance with machine learning on the production machine in the casting factory. With the obtained data, using Principal Component Analysis and Random Forest machine learning methods, unsupervised and supervised maintenance time estimations were performed with an accuracy of $85.17 \%$.
\end{abstract}

Keywords: Industry 4.0, Machine Learning, Predictive Maintenance.

\footnotetext{
*Sorumlu Yazar: hakanceyhan83@gmail.com
} 


\section{Giriş}

Endüstri 4.0 çağında yapay zeka imalat endüstrisini dönüştürüyor. Nesnelerin interneti (Internet of Things - IoT) ve makine ögrrenimi yöntemlerinin ortaya çıkmasıyla birlikte üretim sistemleri, insanlar, makineler, sensörler vb. ile gerçek zamanlı iletişim ve iş birliği yoluyla fiziksel süreçler izlenebilir ve akıllı kararlar alınabilir. Yapay zeka, üreticilerin deneyimlerden öğrenen makine öğrenimi teknolojilerini kullanarak ekipman arıza süresinin azaltılmasına, üretim hatalarının tespit edilmesine, minimum duruş süresi sağlayabilmesine ve tedarik zincirini iyileştirebilmesine olanak tanır (Angelopoulos vd., 2020). Bu teknolojilerin son uygulamalarından biri de kestirimci bakım (predictive maintenance) sistemleridir. Tahmine dayalı bakım, üretim ekipmanının bakıma ihtiyaç duyacağı tam zamanı tahmin etmek için endüstriyel IoT teknolojilerini makine öğrenimi ile birleştirerek sorunların çözülmesine ve uyarlanabilir kararların zamanında alınmasına olanak tanır (Carvalho vd., 2019).

Geçmişten günümüze yaşanan endüstriyel devrimler iş süreçlerinin verimliliğini artırmıştır. Büyük bir işgücü ve dolayısıyla düşük üretkenlik gerektiren görevleri yerine getirmede insanın kapasitesini artıran gelişmelere "Endüstri Devrimi” denir (Martins vd., 2020).

Yeni teknolojileri adapte etme ve kullanma ihtiyac1, endüstriyi yeni bir çağa doğru evrimleştirdi. Veri miktarı, yeni cihazlar, bağlantı teknolojileri, kişiselleştirme ve kontrollü üretim endüstri 4.0 olarak adlandırılan süreci doğurdu. Almanya'da endüstri alanında yenilik ve değişim taleplerini karşılayabilmek için oluşturulan terimin adı "dördüncü sanayi devrimi" olarak ilan edildi (Zonta vd., 2020).

$\mathrm{Bu}$ çalışmanın ana amacı, kestirimci bakım benzer modeli ile makine öğrenmesi metodolojisi kullanılarak makinenin sağlık durumunu tespit edebilmektir. Bu sayede makine arıalanmadan önce bir erken uyarı sistemi oluşturarak bakım sayısı ve zamanı optimize edilebilecektir.

$\mathrm{Bu}$ çalışmada anlatılacak olan kestirimci bakım sistemini anlayabilmek için endüstriyel devrim dönemleri de sonraki bölümlerde kısaca açıklanacaktır.

\subsection{Endüstriyel Devrim Dönemleri}

Endüstri, insan gücüne dayalı üretimden, üretim hızlarının ve kalitesinin arttığ 1 çok daha kontrollü olduğu bugünün şartlarına ulaşırken aşağıdaki dönemlerden geçmiştir (Şekil 1).

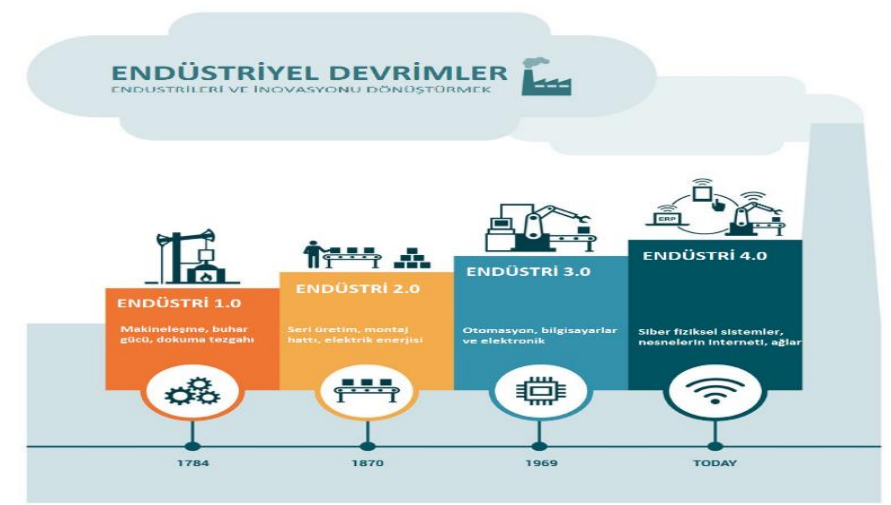

Şekil 1. Endüstriyel Devrimler (Figure 1. Industrial Revolutions) (Agrawal, 2017)

\section{Endüstri 1.0 (18. Yüzyıl)}

Su ve buhar enerjisi ile çalışan mekanik üretim sistemlerinin ilk örnekleri ortaya çıkmıştır.

\section{Endüstri 2.0 (20. Yüzyıl Başlangıcı)}

İlk üretim hatlarının kurulduğu, iş bölümüne dayalı, elektrik enerjisinden faydalanılan kitlesel üretimin devreye girişi başlamıştır.

\section{Endüstri 3.0 (1970’lerin Başı)}

Otomasyon dönemini başlatan, ilk programlanabilir mantıksal denetleyicilerin (PLC) kullanıldığı, elektronik ve bilgi teknolojilerinin devreye girişi bu yıllardan sonra başlamıştır.

\section{Endüstri 4.0 (21. Yüzyıl)}

Otonom makineler, siber fiziksel sistemler, yatay dikey entegrasyon, nesnelerin interneti, makine öğrenimi, büyük veri ve analitiği, bulut bilişim, artırılmış gerçeklik, siber güvenlik, 3D yazıcılar bu son endüstriyel devrimin ürünleri olarak gösterilebilir.

Özellikle günümüzde endüstri 4.0 ile birlikte çeşitli alanlarda benzeri görülmemiş teknolojik ve bilimsel gelişmeler yaşanmaktadır. $\mathrm{Bu}$ gelişmeler ile birlikte nihai amaç iş süreçlerinin verimliliğini artırmaktır. Bilgiye erişim şekillerinde de değişiklik olmuş, çok çeşitli kaynaklardan (sensörler, akıllı kontrol sistemleri, giyilebilir teknolojiler vb.) çok daha hızlı bir şekilde veri toplanabiliyor olmasına rağmen artık daha karmaşık bir yapıya bürünmüştür. Bu karmaşık ve büyük verinin anlamlı bir hale getirilebilmesi amaciyla işlenmesi, günümüzde verimliliği artırmak için gerekli olan önemli parametrelerden biri haline gelmiştir. Özellikle sensör teknolojilerinin gelişmesi, makine-makine (M2M), makine-insan (HMI) haberleşmesi ve standartlarının olgunlaşması (OPC UA), nesnelerin interneti, yapay zeka ve büyük veri analitiği ile karmaşık sorunların üstesinden gelinebilmesi sağlanmıştır.Geleneksel bakım süreçleri de bu gelişmelerden nasibini almış, arızi bakım ve koruyucu periyodik bakım dışında makine verilerinin analizinden yola çıkarak arıza oluşmadan önceki sürecin tahmin edilmesiyle kestirimci bakım yapılabilmesi olanaklı hale gelmiştir.

Endüstriyel devrimler, endüstriyel üretkenliği ve karmaşıklığı artırmıştır. Mühendisler, belirli algoritmalarla kontrol edilebilen makineleri performansını iyileştirebilmek amacıyla kendi kendine öğrenebilen ve her geçen gün daha iyiye giden makinelere dönüştürmeyi amaçlarlar. $\mathrm{Bu}$ amaç doğrultusunda da, öncelikle fabrikadaki hatlardan/makinelerden makine-makine ve makine-insan arabirimleri aracılığı ile sağlıklı bir şekilde verilerin toplanması ilk adımlardan biridir.

\subsection{Haberleşme ve Veri Toplama}

$\mathrm{Bu}$ çalışmada bahsi geçen döküm fabrikasındaki verileri toplamak için OPC UA haberleşme standardı kullanılmıştır. OPC UA (OLE for Process Control Unified Architecture), ham verilerin ve önceden işlenmiş bilgilerin üretim sahasından üretim planlama sistemlerine güvenilir şekilde taşınabilmesi için geliştirilmiş bir OPC Foundation teknolojisidir (Cavalieri ve Cutuli, 2010).

Günümüzde endüstriyel alanda her türden makineler farklı marka ve model adı altında makine-makine, makine-insan ve CRM (Customer Relationship Management) sistemleri ile sürekli iletişim sağlayabilmeleri gerekmektedir. Bu gereklilik ile her marka ve modelin kendi kapalı devre çözümleri maliyetli ve 
sadece ilgili marka ve model için geçerli olmaktaydı. OPC Foundation'ın Classic OPC ve OPC UA standartları, makineler arası iletişimi marka modelden bağımsız hale getiren standartlar olarak kabul görmüştür.

\subsection{Kalan Faydalı Ömür}

Kestirimci bakım, makinenin/ekipmanın belirli bir periyottaki sağlık durumunu tahmin etme süreci olarak tanımlanabilir. $\mathrm{Bu}$ tahmini yaparken de makineden sensörler vasıtası ile alınan sıcaklık, basınç, gürültü, titreşim, çekilen akım, ortam sıcaklığı gibi çeşitli verilerin analizinden elde ettiği sonuçları kullanır.

Arıza oluştuktan sonra yapılan bakımlarda arıza tespiti, bakım süresinin uzayabilmesi, oluşan arızanın bir takım farklı arızaları tetikleyebilmesi unsurlarından dolayı verimliliği olumsuz etkileyebilmektedir. Buna karşıllık arızi bakımı en aza indirmek amacıyla arıza oluşmadan önce yapılan periyodik bakımların sıklaştııılması ise toplam bakım süresini artırmakta ve verimliliği düşürebilmektedir. Kestirimci bakım tam da bu noktada yapılması gereken bakımın zamanını tespit etmeyi amaçlamaktadır.

Kestirimci bakımın amacı "Kalan Faydalı Ömür”ü (Remaining Useful Life - RUL - KFÖ) tahmin etmektir. Bu sayede makinenin sağllk durumu tespit edilebilir ve oluşabilecek arızalar önceden tahmin edilebilir. Bunun sonucunda da bakım planlaması yapılarak gereksiz bakımların önüne geçilmiş ve dolayısı ile makine verimliliğine ciddi ölçüde katkı sağlanmış olur.

KFÖ tahmini, makinelerin gelecekteki performansını tahmin etmek ve makinelerin arıza durumuna geçmeden önceki kalan süreyi elde etmek için tahmin yöntemlerini kullanan bir süreçtir (Lei vd., 2016).

KFÖ tahmininde genel olarak 3 model mevcuttur;

- Hayatta Kalma Modeli: Tam olarak arıza oluştuğu sıradaki veriler bilindiği takdirde,

- Bozulma Modeli: Elde arıza verileri yoksa ancak arızayı işaret eden bir eşik değeri bilindiği takdirde,

- Benzer Modeli: Makinenin/ekipmanın sağlıklı çalış̧ı̆̆ı bilinen bir t zamanından itibaren arıza oluşuncaya kadar ki süreçte tüm veriler bilindiği takdirde uygulanır (Özkat, 2021).

$\mathrm{Bu}$ çalışmada bir döküm fabrikasında bulunan döküm makinesi verileri üzerinde izleme yapılarak elde edilen veriler üzerinde çalışılmıştır. Makinede 8 duruş tanımı mevcuttur.

\section{1- Acil Stop}

2- Termik Attı

3- Mikser Motoru Sürücü Arızas1*

4- Hava basıncı düşük

5- Konveyör Arızası

6- Malzeme Sıkışması

7- Kalıp Bekleme

8- Mekanik Arıza

Mikser motoru sürücü arızası dışındaki duruş tanımlarının bir kısmı sistem dışından gelen müdahaleler, bir kısmı da ani oluşan üretim bandı duruşlarından kaynaklanmaktadır. Mikser motoru sürücü arızası karışım materyallerinin zaman içinde mikser ve bağlantı ekipmanlarının içinde akışkanlığını kaybetmesi sonucu oluşmaktadır. Mikser motoru sürücü arızası oluştuğunda arızi bakım süresi hem uzun olabilmekte hem de başka mekaniksel arızalara sebebiyet verebilmektedir. $\mathrm{Bu}$ da verimliliği ciddi anlamda olumsuz etkilemektedir. $\mathrm{Bu}$ yüzden mevcut çalışmada yalnızca mikser motoru sürücü arızasının önceden tespit edilebilmesi amaçlanmıştır.

$\mathrm{Bu}$ çalışma 6 bölümden oluşmaktadır. 2. Bölümde bakım yaklaşımları incelenmiştir. 3. Bölümde makine öğrenmesi algoritma çeşitleri ve projede kullanılan makine öğrenmesi algoritmaları hakkında genel bilgiler yer almaktadır. 4. Bölümde projede kullanılan materyaller ve metotlar açıklanmaktadır. 5. Bölümde uygulanan projenin sonuçları irdelenmektedir. 6 . Bölümde ise nihai sonuç açıklanmış ve çalışmanın geliştirilmesi ile ilgili tavsiyeler yer almaktadır.

\section{Bakım Yaklaşımları}

Üretim sistemlerinde verimliliği artırmanın en önemli koşullarından biri üretim sisteminin durmaksızın stabil olarak çalışmasını sağlamaktan geçer. Bu amaçla bakım yaklaşımları hayati öneme sahiptir. Beklenmedik anlarda oluşan arızaların bakımları plansız bakım, arıza oluşmadan önce yapılan ve arızanın önüne geçmeyi amaçlayan bakımlar ise planlı bakımlar olarak ele alınır. Şekil 2'de bakım yaklaşımları ve bu yaklaşımların verimliliğe etkileri gösterilmiştir.

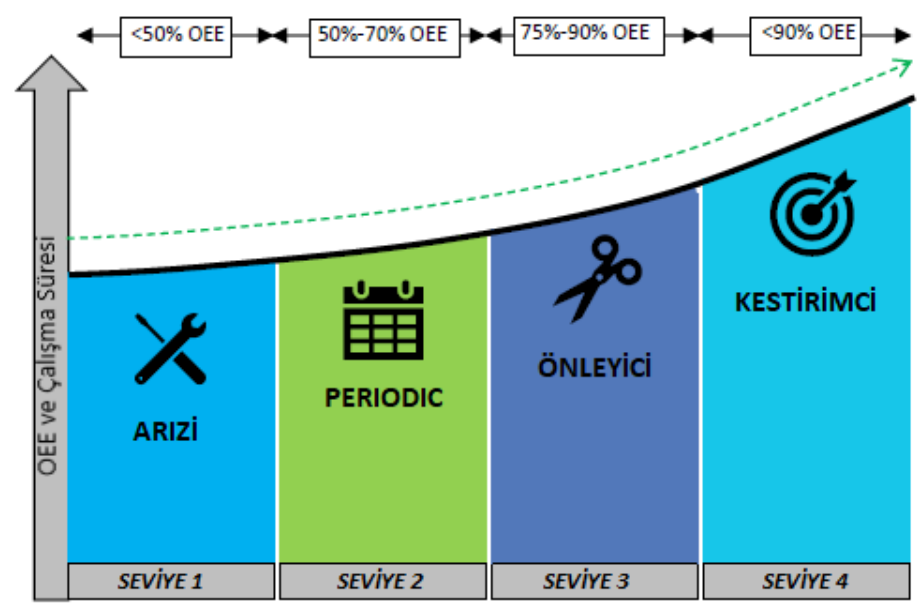

Şekil 2. Bakım Türleri (Figure 2. Types Of Maintenance)

(Çınar vd., 2020)

\subsection{Arızi (Düzeltici) Bakım (Reactive Maintenance)}

Arızi bakımda sistem arızalandıktan sonra tekrar çalışır hale gelebilmesi için onarımlar yapılır (Özgür-Ünlüakın vd., 2019). Beklenmedik bir anda oluşan arızadan hemen sonra sistemin tekrar eski durumuna dönebilmesi amacıyla yapılan tamirat ve onarım çalışmalarıdır (Oktar, 2014). Sistemde öncelikle bir arıza veya performans düşüşü beklenir. $\mathrm{Bu}$ gerçekleştikten sonra yapılan bakıma arızi veya reaktif bakım denir. Plansız bir bakım türüdür. Bakım maliyeti düşük olsa da yapılan üretime göre meydana gelen arıza süresi göz önüne alındığında genel verimliliği düşürebilir. Arıza oluştuğunda bakıma müdahale ve bakım süresi önemlidir. Tespiti zor bir arıza veya tecrübesiz bakımcıların elinde bakım süresinin uzaması verimliliği olumsuz etkiler. Ayrıca yedek parça ihtiyacı söz konusu olduğunda depoda bu parça bulunmuyor ise tedarik süreci ile birlikte bu süre daha da uzayabilir. Bununla birlikte oluşan arızanın başka arızaları tetikleyebilme ihtimali de vardır. 


\subsection{Periyodik Bakım}

$\mathrm{Bu}$ yaklaşımın amacı, arıza oluşmadan önce makinenin arızalanmasına sebep olabilecek bileșenlerinin bakımının yapılmasıdır (Gedikli vd.,2021). Çok sık yapılırsa işletme maliyetlerini artıran gereksiz bakımlara yol açabilir.

Üretim alanlarında bakım planlama biriminin belirlemiş olduğu, yağlama, parça değişimi gibi sistemin genel kontrollerinin yapıldığı düzenli olarak gerçekleştirilen bakımlardır. Sağlıklı bir planlama yapıldığı takdirde endüstride kullanılabilecek uygunlukta ve üretimin sürekliliğini artıran bir yaklaşımdır (Calayır vd.,2021).

Endüstriyel ortamlarda en sik görülen bakım stratejilerindendir. Bakımı yapılacak ekipmanın belirli zaman veya üretim periyoduna göre düzenli olarak bakıma alınması esasına dayanır. Bu zaman dilimi hesaplanırken optimum zaman periyodunun belirlenebilmesi için ekipmanın iyi tanınması gerekir. Burada zaman periyodları belirlenirken minimum plansız bakım oluşmasının sağlanmasına gayret edilir. Periyodik koruyucu bakımın uzun aralıklarla yapılması plansız duruşlara neden olacağı gibi, kısa aralıklarla yapılması da bakım maliyetlerinin artmasına sebebiyet verecektir.

\subsection{Duruma Dayalı Bakım (CBM)}

Duruma dayalı bakımın (CBM) makine bakım stratejisini geliştirmek için etkili bir yöntem olduğu genel olarak kabul edilmektedir. Klasik bir yaklaşım olan arızalandıktan sonra bakım yapılan uygulamalardan, arıza gerçekleşmeden önce önleme yaklaşımına geçiş için etkili bir yöntem olduğu genel olarak kabul edilmektedir. Arızi bakım, sistemde arıza meydana geldiğinde yapılırken, kestirimci bakım, sistemde beklenmeyen arızaları önlemek amacıyla ardışı revizyonları planlamak için istatistiksel makine bilgisini ve operasyonel deneyimi kullanır (Tahan vd., 2017).

Duruma dayalı bakımda makine sürekli izlenir. Belirli parametreler için eşik değerler aşıldığı takdirde bakım yapılır. Periyodik bakımdaki gibi düzenli aralıklarla bakım yapılmaz.

\section{4. Önleyici Bakım (Proaktif Bakım)}

Arızaların kök nedenlerini tespit etmek ve ortadan kaldırmak için gerçekleştirilen bakım faaliyetidir. Kestirimci bakım ve önleyici bakım tanımları göz önünde bulundurulduğunda, kestirimci bakımın veri odaklı bir strateji olduğu, önleyici bakımın ise model tabanlı bir çözüme odaklandığı söylenebilir (Wang vd., 2020).

Önleyici bakımın amacı arızaya sebebiyet veren etkenleri mümkün olduğunca ortadan kaldırmaya yöneliktir. Tüm arızaların ortadan kalkması pek mümkün olmasa da plansız bakımların sayısını minimuma indirmeye yardımcı olur. $\mathrm{Bu}$ tür bir bakımda da önleyici bakımın uygulanabilmesi için yine ekipmanın iyi tanınması gerekmektedir. Örneğin nemden kaynaklı bir arıza oluşması söz konusu ise ekipmanların nemden arındırılması veya çalışma ortamının nem oranının kontrol altına alınması önleyici bakım kapsamındadır.

\subsection{Kestirimci Bakım (Predictive Maintenance)}

Kestirimci bakım, sistemlerin en olası arıza sonucunu tahmin etmek için verilerin, makine öğrenme tekniklerinin ve istatistiksel algoritmaların kullanılması olarak adlandırılır (Kimera ve Nangolo, 2020). Kestirimci bakım, bir makinenin sağlıklı çalışıp çalışmadığını tahminleme ve sensörler veya akııllı kontrol cihazları ile elde edilen verileri makine öğrenimi algoritmalarıyla modelleyerek, bakım çalışmaları ile ilgili en iyi kararı verme süreci olarak tanımlanır (Özkat, 2021). Kestirimci bakımın özü, bir sonraki arızayı, arıza meydana gelmeden önce tahmin etmektir (Ayvaz vd.,2021).

Bir ekipmanın sağlık durumuna ilişkin tahmine dayalı olarak bakımının yapıldığı kestirimci bakım sistemleri, geçmiş veriler, tanımlanmış sağlık faktörleri, istatistiksel çıkarım yöntemleri ve mühendislik yaklaşımlarına dayalı tahmin araçları sayesinde, arızaların önceden tespit edilmesine ve arıza öncesi müdahalelere olanak tanır (Çınar vd., 2020).

Periyodik bakımın dezavantajlarından biri ekipmanlar daha uzun süre arızalanmadan işleyişine devam edebilecek ve sistem çalışmasını sürdürebilecek durumda olsa bile bakım yapılmasıdır. Bu da bakım maliyetlerini artırır. Bununla birlikte bakım esnasında üretim yapması gereken hat, bu süreyi bakımda geçirdiği için bu hattın verimliliği düşer.

Endüstri 4.0 kavramı ile birlikte makinelerin/hatların gerçek zamanlı olarak izlenebilirliği sağlanabilmektedir. Sensörler aracılığı ile hattın çeşitli bilgileri gerçek zamanlı olarak izlenerek bakım yapılması gerekip gerekmediği öngörülebilir (Bektaş O., 2020). Kestirimci bakımın amacı sensörler aracılığı ile sistemin çeşitli bileşenlerini takip ederek, kalan faydalı ömrü tespit edip bakımın gerekip gerekmediğini öngörmektir. Şekil 3'de sistem şartlarına göre uygulanabilecek bakım türleri ve zamanları gösterilmiştir.

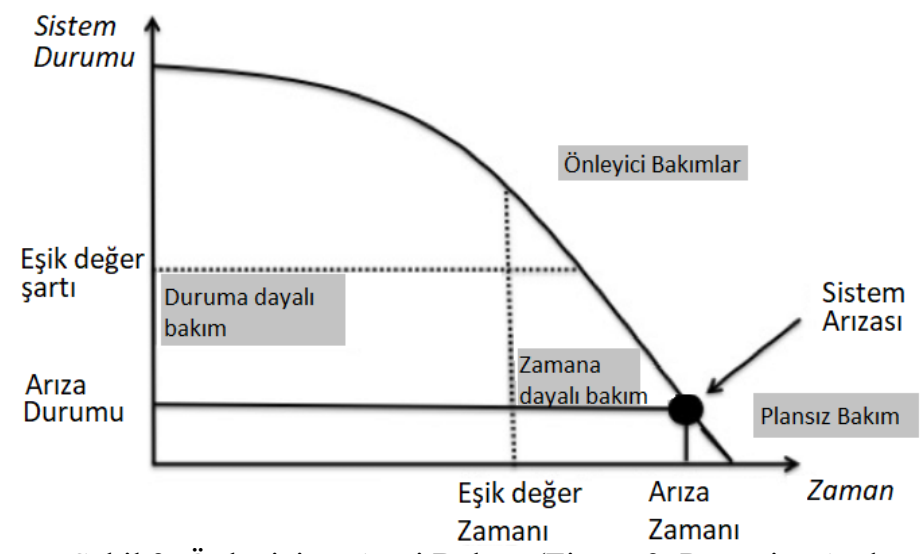

Şekil 3. Önleyici ve Arızi Bakım (Figure 3. Proactive And Reactive Maintenance) (Sirvio, 2015)

\section{Machine Learning}

Yapay zekanın bir alt dalı olan makine öğrenmesi, doğrudan programlama yapmadan, bunun yerine verilerden sisteme öğrenme ve öğrendiklerini geliştirebilme becerilerini kazandıran bir disiplindir.

Her gün büyük miktarda veri üretilir ve paylaşılır. Anlamlı sonuçlar elde etmek için bu kadar büyük miktarda veriyi analiz etmek zahmetli bir iştir ve manuel olarak uygulamaya çalışmak imkansızdır. Verileri analiz ederek geliştirilen yöntemler ile kalıplar bulup buradan anlamlı sonuçlara ulaşmak herhangi bir uygulama alanının bilinçli kararlar alabilmesi için gereklilik arz eder. Ancak daha iyi tahminler yapmak için rastgele orman, lojistik regresyon, destek vektör makinesi ve kümeleme algoritması gibi denetimli veya denetimsiz çeşitli makine öğrenme algoritmalarını uygulamak mümkündür (Chazhoor vd., 2020). 
Amaca bağlı olarak kullanılabilecek 4 farklı makine öğrenmesi yaklaşımı mevcuttur (Masani vd.,2019).

\section{$>$ Denetimli (Supervised) Öğrenme \\ $>$ Denetimsiz (Unsupervised) Öğrenme \\ $>$ Yar1-Denetimli (Semi-Supervised) Öğrenme \\ $>$ Pekiştirmeli (Reinforcement) Öğrenme}

Denetimli (Supervised) Öğrenme; makine öğrenimi etiketli veriler kullanılarak gerçekleştirilir. Denetimli makine öğreniminde bağımsız verilerle birlikte bağımlı değișken de verilerek eğitim sağlanır. Oluşturulan bu model daha sonra verilen bağımsız değişkenleri kullanarak hedef değişkeni tahmin eder. Sınıflandırma ve regresyon amaçlı kullanılır. Doğrusal regresyon (lineer regresyon), lojistik regresyon (logistic regression), naïve bayes, destek vektör makineleri (support vector machines), karar ağaçları (decision tree) gibi denetimli makine öğrenmesi algoritmaları mevcuttur.

Denetimsiz (Unsupervised) Öğrenme; etiketlenmemiş, belirsiz veriler üzerinde çalışır. Veriler etiketli olmadığından bu verileri kümeleyerek anlam çıkarmayı amaçlar. K-ortalamalar (k-means), k-en yakın komşu (k-nearest neighbour), apriori algoritması, temel bileşenler analizi (principal component analysis) birer denetimsiz makine öğrenme algoritmalarıdır.

Yar1-Denetimli Öğrenme; denetimli ve denetimsiz öğrenme tekniklerini içerisinde barındırır. Etiketlenmemiş büyük miktarda veri ile birlikte etiketlenmiş küçük miktarda veriyi kullanan bir yaklaşımdır.

Pekiştirmeli (Reinforcement) Öğrenme; deneme yanılma yolunu benimseyerek başarıya ulaşmayı hedefleyen bir yöntemdir. $\mathrm{Bu}$ öğrenme biçiminde ajan çevresini ölçebilir ve buna göre bir aksiyon alabilir. Bu aksiyona karşıllk bir tepki bekler ve bu tepkiler ödül sistemi içerisinde değerlendirilir. Kazanılan ödül baz alınarak ajan eğitilmiş olur. Ödül-ceza sistemini baz alan bir yaklaşımdır.

\subsection{Rastgele Orman (Random Forest)}

$\mathrm{Bu}$ yöntem, birçok özelleşmiş karar ağacının birleşimi olarak ifade edilebilir. Girdi-çıktı ilişkisi, makine tarafından deneysel veriler yardımıyla belirli güven aralıklarında öğrenilir. Tahmin modelinin başarısı, makine tarafindan yeterli öğrenme sağlandıktan sonra doğrulama verilerinin test edilmesiyle belirlenir.

Breiman tarafindan önerilen rastgele orman yaklaşımı, birçok karar ağacına sahip bir makine öğrenme algoritmasıdır. Torbalama ve Rastgele Alt Uzaylar yöntemlerinin bir birleşimidir. $\mathrm{Bu}$ yöntem son yıllarda hem regresyon hem de sınıflandırma problemlerinde başarısını kanıtlamış ve birçok farklı alanda kullanılan en iyi makine öğrenmesi algoritmalarından biridir. RO algoritmasında veri seti öncelikle, öğrenme eğitim verisi (in-Bag) ve öğrenme düzeyini test etmek için test verisi (out of bag) olmak üzere rastgele iki kısma ayrılır. Daha sonra, veri setinden rastgele birçok karar ağacı oluşturulur. Her ağacın dallanması, düğüm noktalarında rastgele seçilir. RO nihai tahmini, her bir ağaçtan elde edilen tüm sonuçların ortalamasıdır. $\mathrm{Bu}$ nedenle, her bir ağaç belirli ağırlıklarda RO tahminini etkiler. Bu yöntemde her ağaç tek tek incelenmez. RO algoritmas1, alt kümelerden rastgele eğitim verisi alma ve rastgele algoritma ile ağaç oluşturma özelliğinden dolayı diğer makine öğrenmesi algoritmalarından daha güçlüdür (Yeşilkanat, 2020).

\subsection{Temel Bileşenler Analizi (Principal Component Analysis)}

Birçok özelliğe sahip büyük veri kümelerinde bilgilerin çoğunu korurken bir dizi boyut küçültme tekniği kullanılarak değişkenlerin sayısını azaltmak mümkün olabilmektedir. Bunlar arasında en yaygın kullanılanı temel bileşenler analizidir (TBA) (Lauro ve Palumbo, 2000).

Temel bileşenler analizi, birçok değişkenden oluşan bir veri setinde bulunan bilgiyi daha az değişkenle ve minimum bilgi kaybıyla ifade etmeye çalışan bir tekniktir. Büyük boyutlu veri setleri içindeki boyutsallığı azaltır. Böylece minimum kayıpla boyut indirgenmiş olur. Üç amacı vardır; verilerin boyutunu azaltma, tahminleme, veri seti boyutunu küçülterek analiz yapılması amacıyla görüntülemektir.

\section{Materyal ve Metot}

Teknolojik gelişmeler ile son yıllarda veriye erişim şekillerinde de değişiklikler meydana gelmektedir. Geçmişte sınırlı cihazlardan veri alınabiliyorken, nesnelerin interneti kavramının hayatımıza girişiyle birlikte bugün çok çeşitli cihazlardan veri alınabilmektedir. Sadece kullanıcı girişleri ile elde edilen bilgiler değil, cihazlarla doğrudan haberleşerek gerçek zamanlı bilgiler elde edilebilmektedir. Bununla birlikte cep telefonları, giyilebilir teknolojiler (akillı saatler, akı1lı gözlükler, sensör teknolojileri...) de günlük hayatın vazgeçilmez bir parçası haline gelmiştir. Özellikle endüstriyel ortamlarda sensörler aracılığı ile alınabilen veriler bize geniş bir çalışma alanı sunabilmektedirler.

Bir kestirimci bakım uygulaması yapılabilmesi için öncelikle ilgili makinenin verileri sensörler ve diğer akıllı kontrol sistemlerine erişim aracılığıyla alınabilmelidir. $\mathrm{Bu}$ uygulamada döküm makinesinin verilerinin toplanabilmesi için bir Siemens PLC S7-1200 kullanılmıştır. Bu çalıșmada kullanılan donanım ve yazılımların listesi aşağıdaki şekildedir.

$>$ PLC (Siemens S7 -300, Siemens S7-1200)

$>$ Veri toplama servis yazılımı (Araştırmacı tarafından yazılmıştır.)

$>$ Endüstriyel PC (Data Collection Box PC) Endüstriyel Box PC, Intel® Pentium ${ }^{\circledR}$ N4200 $2.5 \mathrm{GHz}$, 2 HDMI, 2 GbE LANs, 6 USB 12V/36W AC/DC adapter and EU power cord, Win 10 IoT OS

$>$ SQL Server 2018 Professional Edition

$>$ MES (Manufacturing Execution System) arıa tanımlama arayüzü. (Araştırmacı tarafından yazılmıştır.)

$>$ MES bakım arayüzü. (Araştırmacı tarafından yazılmıştır.)

PLC aracılığı ile makinenin bilgileri anlık olarak kaydedildi ve veri seti olarak hazırlandı. Bu çalışmada makineden, çalışma durumu, üretim sayısı (adet), üretim miktarı $(\mathrm{kg})$, ürün üretim süresi, mikser motor durumu, reçete yükleme numarası, mikser motor titreşim, mikser sıcaklık, mikser hızı (rpm), mikser basınç, akım faz1, akım faz2, akım faz3, belirlenmiş 8 adet alarm durumu, tarih/saat gibi bilgiler alınmıştır. Aynı anda birden fazla alarm gelebildiğinden dolayı her alarm tipi için farklı bir alan belirlenmiştir.

Sistemin otomasyon teknolojileri tarafindaki kontrolünden sorumlu cihaz olan PLC S7-300 ile OPC UA aracılığı ile doğrudan haberleşme sağlanamayacağından PLC S7-300 ile 
PLC S7-1200 arasında S7 bağlantı protokolü ile haberleşme sağlanmıştır. Yukarıda bu çalışma için ihtiyaç duyulabilecek veriler PLC üzerinden bu haberleşme protokolü ile PLC S71200'e taşınmıştır. Şekil 4'de de görüldüğü üzere elde edilen veriler PLC-1200 üzerinde toplanmış ve OPC UA destekli bu PLC (S7-1200) ile haberleşen endüstriyel bir bilgisayar üzerinde çalışan veri toplama servisi aracılığı ile saniyede bir bu veriye erişecek şekilde kodlanarak merkezi sunucu üzerindeki veri tabanına yazılmıştır.

Arıza oluştuğu takdirde makine arıza sebebi sistem tarafindan otomatik olarak tespit edilemediyse belirsiz arıza bilgisi bir arayüz aracılığı ile operatörlere iletilir. Bu arayüz hem izleme hem de arıza bilgilerinin girişlerinin yapılabilmesini sağlayabilmektedir. Gelen uyarı ile operatörden bu arızanın sebebinin girilmesi talep edilir. Böylece oluşan duruşların sebepleri de kiosk aracılı̆̆ olur.

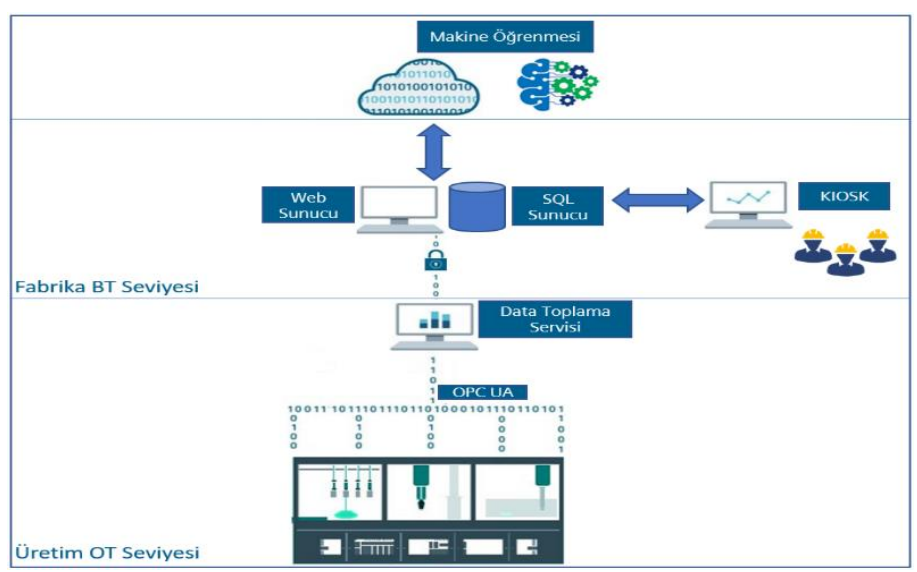

Şekil 4.Uygulama Çalışma Şablonu (Figure 4. Architectural Overview)

\section{Veri seti:}

16/04/2021-15/09/2021 tarihleri arasında gerçekleşen 3.801.250 satır veriden oluşur. Veri seti özellikleri Tablo 1 'de gösterilmiştir.

Tablo 1.Veri Seti Özellikleri ve Açıklamaları (Table 1. Dataset)

\begin{tabular}{|l|l|}
\hline ObjectID & Satır numarası \\
\hline Machine_Working & Çalışma durumu \\
\hline Production_Count & Üretim sayısı (Adet \\
\hline Production_Amount & Üretim miktarı (Kg) \\
\hline Worktime & Ürün üretim süresi (sn) \\
\hline Engine_Status & Mikser motor durum \\
\hline Charge & Reçete yükleme numarası \\
\hline Mixer_Vibration & Mikser motor titreşim \\
\hline Mixer_Actual_Temperature & Mikser sıcaklık \\
\hline Mixer_Working_Speed & Mikser hızı (RPM) \\
\hline Mixer_Actual_Pressure & Mikser basıç \\
\hline Current_1 & Akım Bilgisi Faz 1 \\
\hline Current_2 & Akım Bilgisi Faz 2 \\
\hline Current_3 & Akım Bilgisi Faz 3 \\
\hline Alarm_1 & Acil Stop \\
\hline Alarm_2 & Termik Att1 \\
\hline Alarm_3 & Mikser Motoru Sürücü Arıaas1 \\
\hline Alarm_4 & Hava basıncı düşük \\
\hline Alarm_5 & Konveyör Arızas1 \\
\hline Alarm_6 & Malzeme Sıkışması \\
\hline Alam_7 & Kalıp Bekleme \\
\hline Alarm_8 & Mekanik Arıza \\
\hline Datetime & Tarih/Saat \\
\hline
\end{tabular}

Veri setimize öncelikle veri ön işleme adımları uygulandı. NULL değer içeren az sayıdaki veri, veri setinden çıkarıldı. Farklı tarih formatları düzenlendi. Makine çalışma saatleri ile uyuşmazlık gösteren veriler kirli veri olarak nitelendirilip veri setinden çıkarıldı. Elde edilen veri setinde, makinenin sağlıklı çalışmaya başladığı durumdan öngörmek istediğimiz arıza verisi gelene kadar ki veri blokları kullanıldı.

Kestirimci bakımda makinenin t anında yalnızca çalıştığı ya da arızalı olduğu bilgisini tahmin edebilmek yeterli değildir. Önleyici tedbirlerin zamanında alınabilmesi için o üretim sisteminin ihtiyaç duyduğu arızaya kalan süreyi doğru tahmin edebilmek gereklidir. $\mathrm{Bu}$ nedenle bu problem bir siniflandırma probleminden ziyade bir regresyon problemi olarak ele alınabilir.

İlgili veri seti hem denetimli hem de denetimsiz makine öğrenmesi algoritmalarından birine ayrı ayrı uygulanmıştır. Literatür taraması sonucu regresyona uygulanabilir olan ve tahmin gücünün yüksek olduğu bilinen denetimli makine öğrenmesi algoritmalarından rastgele orman, denetimsiz makine öğrenmesi tarafinda temel bileşen analizi kullanılmasına karar verilmiştir.

Makine çalışma parametreleri 6 ay boyunca izlendi. $\mathrm{Bu}$ arızalar gerçekleşinceye kadar ki sağlıklı makine çalışma parametreleri üzerinde çalışıldı.

Temel bileșen analizi tekniği ile 16 özellik içerisinden vibrasyon, akım ve sicaklık parametrelerinin bilginin \%99'unu kapsayan öznitelikler olduğu tespit edilmiştir. Her iki makine öğrenmesi yöntemi için bu 3 özellik dışındaki özellikler elenmiştir.

Rastgele orman modeli ile kullanılan metodolojide, arızanın oluştuğu zaman bilindiği için bu arızaya kadar ki kalan zamanı kalan faydalı ömür olarak hesaplayıp yeni bir sütun olarak veri setimize ekledik. Veri setimizi \%54 eğitim (77.487 adet), \%46 test $(66.052$ adet) veri seti olarak ikiye ayırdık. Denetimli makine öğrenmesi algoritmalarından rastgele orman algoritması ile modelimizi oluşturduk. Kalan faydalı ömrü bulmaya odaklı çalışma, alarm tespitine bir regresyon problemi olarak yaklaşabilmemizi sağlamıştır. Böylelikle arızaya ne kadar süre kaldığının tahmini yapılabilmiştir. Model oluşturulurken n_estimators (ağaç sayısı) parametresi olarak 1000 değeri alınmıştır.

Temel bileşen analizi modeli ile kullanılan metodolojide, temel bileşen analizi yardımıyla çalışma koşullarını belirleyen en etkili bileşenler tespit edildi. Burada veriyi en iyi açıklayan bileşenleri bulmak amaçlanmıştır.

Veri seti öznitelik mühendisliği (feature engineering) uygulamak amaciyla pencerelere ayrilır ve her pencere düzeyinde alanların kısa vadeli dağılımını tanımlayan bir dizi istatistiksel nicelik hesaplanır. $\mathrm{Bu}$ nicelikler, daha önce Metallinou ve ekibi tarafından sürekli izleme için başarıyla kullanılmış olan 11 fonksiyon; mean, standard deviation, skewness, kurtosis, range, minimum, maximum, first quantile, third quantile, median quantile ve inter-quantile range'den oluşur (Turker vd., 2017).

Veri üzerinde her bir kayıt için kendisinden önce gelen 12 saatin verisine dair istatistikler hesaplanarak mevcut özelliklerde zenginleştirilmeye gidilmiştir. Mean, standard deviation, skewness, kurtosis, range, minimum, maximum, first quantile, third quantile, median quantile ve inter-quantile range 
istatistikleri veri setinin özellik bilgilerine ilave edilerek özellik sayısı 3'den 36'ye çıkarılmıştır.

Denetimsiz makine öğrenme algoritmalarında etiketli datalardan bahsedilemediği için veri seti $\% 80$ eğitim, $\% 20$ test olarak ayrılmış, metrik olarak da denklem (1) deki formül ile ifade edilen kare tahmin hatası (Squared Prediction Error - SPE) kullanılmışır.

36 özellik arasından TBA uzayında \%99 anlamlılık teşkil eden özellik sayısı 3 olarak tespit edilmiştir. TBA hesaplamasında çıkartılan öz vektörler büyükten küçüğe sıralanarak ilk 3 temel bileşen arasından her bir satır için SPE hesaplaması yapılmıştır.

$$
S P E=\sqrt{\left\{\frac{\sum\left(y-y_{p}\right)^{2}}{n}\right\}}
$$

Eğitim verisi içerisindeki SPE değerlerinin ortalaması üzerinden bir üst sınır belirlenmiş, bu üst sınır test veri setinde alarm üst sınırı olarak kullanılmıştır.

\section{Araştırma Sonuçları ve Tartışma}

\subsection{Random Forest ile Tahminleme Sonucu}

Denetimli makine öğrenmesi algoritmalarından rastgele orman kullanılarak önce regresyon uygulanıp daha sonra KFÖ tahminlerini sınıflandırarak kategorik sonuçlar elde edilmiştir. Belirlenen kategoriler işletmenin ihtiyaçlarına göre farklılık gösterebilir. Mevcut işletme için bakım uyarı sistemi içerisinde makinenin arıalanmasına kalan süre için 3 kategori belirlenmiştir.

- Normal Çalışma (Arızaya kalan süre 10 saatten fazla)

- Uyarı (2 ile 10 saat arası)

- Alarm (2 saatten az)

Normal çalışma kategorisi; makinenin çalışma parametrelerinde herhangi bir anormallik olmadığını ve bakım gerektirmediğini, uyarı; bakımın yakında gerekli olabileceğini, alarm ise bakımın acilen gerekli olduğunu aksi takdirde mikser motor sürücü arızasının gerçekleşebileceğini belirtir.

Şekil 5'de saniye bazında tahmin edilen KFÖ değerleri ile gerçek KFÖ değerleri grafik üzerinde gösterilmiştir. Saniye bazında elde edilen doğruluk değeri (accuracy) \%58,02 olmuștur. Bununla birlikte Şekil 6'da gösterildiği üzere tahmin ve gerçek KFÖ değerleri belirlenen kategorilere göre sınıflandırıldığında ise elde edilen doğruluk değeri \%85,17'dir.

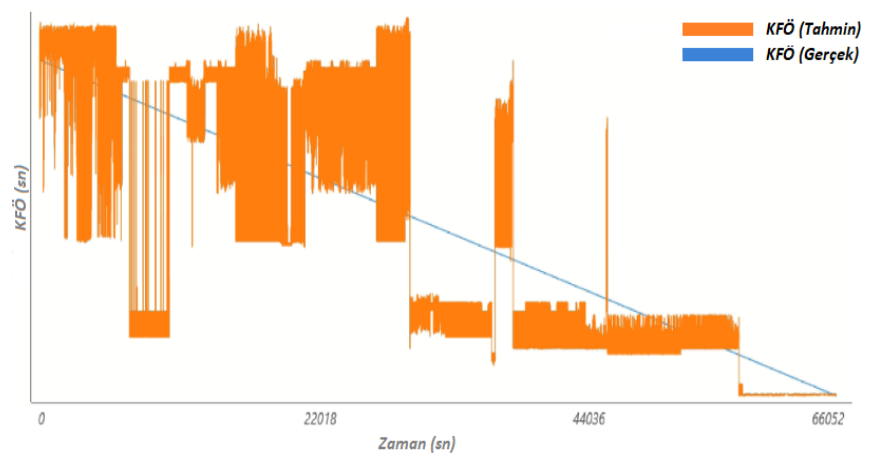

Şekil 5. Gerçek/Tahmin KFÖ Grafiği (saniye) (Figure 5. Truth/Prediction RUL Graph (second))

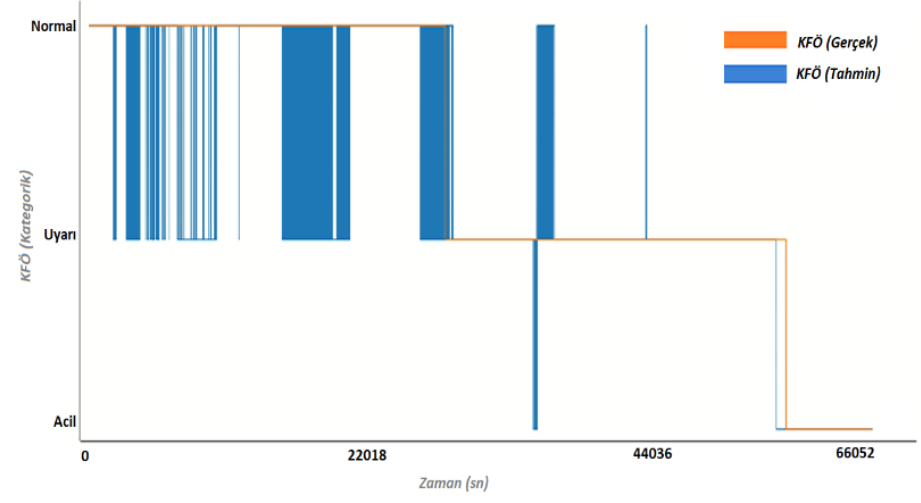

Şekil 6. Gerçek/Tahmin KFÖ Grafiği (kategorik) (Figure 6. Truth/Prediction RUL Graph (categorical))

\subsection{Temel Bileşen Analizi ile Tahminleme Sonucu}

Test veri seti modele uygulandığında modelin başarı tespiti için kare tahmin hatası (SPE) metriği kullanılmıştır. SPE metriği ile test verilerinin $\% 73,4$ ünde anomali tespit edilmiştir. Şekil 7 arızanın gerçekleştiği ana tekabül eden kayıtların PC1 (Principal Component 1), PC2 (Principal Component 2)'ye göre dağılım grafiğini ifade etmektedir.

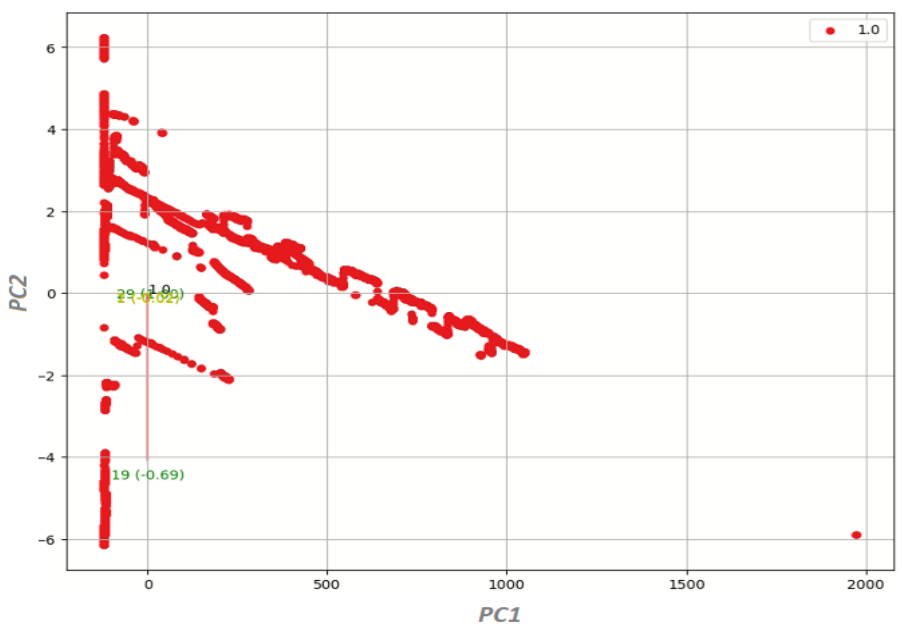

Şekil 7. PC1/PC2 Dağılım Grafiği (Figure 7. PC1/PC2 Distribution Graph)

Bu çalışmada kullanılan veri seti, bir veri toplama sistemi ile döküm fabrikasından elde edildiğinden başka çalışmalarla doğrudan bir kıyaslama yapmak mümkün olmamıştır. Buna rağmen aşağıdaki tabloda bu çalışma ile benzer çalışmalarda elde edilmiş olan doğruluk değerlerinin karşılaştırmasına yer verilmiştir.

Tablo 2.Alternatif Çalışmalar ile Doğruluk Değerlerinin Karşılaştırlması (Table 2. Comparison of Alternative Studies and Accuracy Values)

\begin{tabular}{|l|l|l|}
\hline \multicolumn{1}{|c|}{ Çalışmalar } & \multicolumn{1}{c|}{ Yöntem } & Doğruluk Oranı \\
\hline Mevcut Çalışma & RO & $\% 85,17$ \\
\hline Çalışma 1 (Çınar vd., 2020) & RO & $\% 98,8$ \\
\hline Çalışma 2 (Tessaro vd., 2020) & RO & $\% 88,75$ \\
\hline
\end{tabular}




\section{Sonuç}

Geleneksel arızi, periyodik ve önleyici bakımlar, üretim endüstrilerinde hala yaygın olarak kullanılan bakım yöntemleridir. Arıza gerçekleştikten sonra arıza tespit süresinin uzun olması, yedek parça gereksinimi söz konusu olduğunda parça işletmede mevcut değilse tedarik süresinin uzayabilmesi, oluşan arızanın zincirleme olarak başka arıaları tetikleme ihtimali gibi unsurlar, bakım maliyetlerini artıran unsurlardır. Bununla birlikte periyodik olarak yapılan bakımların periyotları uzun tutulduğunda arızi bakımın artmasına sebep olduğu gibi, kısa tutulduğunda ise sistem uzun süre sorunsuz çalışabilecekken gereksiz bakımlara ve bu nedenle de üretim verimliliğinin düşmesine sebebiyet vermektedir. Mevzu bahis bakım yaklaşımlarının eksikliklerini gidermek ve bu çalışmada üretim endüstrisinde bakımı optimize edebilmek amaciyla makine öğrenmesi yöntemleri kullanılarak kestirimci bakım yaklaşımı uygulandı. Kestirimci bakım makineye ait verileri sürekli bir şekilde gerçek zamanlı olarak takip ederek değişen koşullara rağmen verimliliği en üst düzeyde tutacak şekilde makine bakımı için en uygun zamanı belirler. Böylece arıza oluşmadan önlem alınabilir ve gereksiz bakımların önüne geçilebilir.

$\mathrm{Bu}$ çalışmada, endüstriyel ortamda üretim yapan bir döküm makinesi üzerinde mikser motor sürücü arıza zamanı tahmini için kestirimci bakım uygulaması gerçekleştirildi. Uygulanan modellerin çıktıları göz önüne alındığında, denetimli makine öğrenme modeli rastgele orman ile nispeten daha başarılı sonuçlar elde edildiği gözlemlendi. Bu kapsamda kestirimci bakım uygulamamızın mikser motor sürücü arızasını gerçekleşmeden önce belirlenen kriterlere göre tahmin etme konusunda etkili olduğu söylenebilir. Bu sayede belirtilen arıza gerçekleşmeden önce önlem alınarak arızanın ve üretim verimliliğinin bu durumdan olumsuz etkilenmesinin önüne geçilebilir.

Kestirimci bakım için çalışma yapılacak olan alan ile ilgili veri setleri ve beklentilere göre farklı yaklaşımlar söz konusudur. Dolayısıyla tüm kestirimci bakım uygulamaları için tek bir yaklaşım söz konusu değildir. Bu çalışmada tek bir ürün tipi için farklı duruş sebeplerinden sisteme olumsuz etkileri ve maliyeti çok daha büyük olan mikser motor sürücü arızası gerçekleşme zamanı tahminlemesi üzerinde durulmuştur. Sonraki aşamada veri seti zenginleştirilerek farklı ürün tiplerinde ve farklı arıza tiplerini de tahmin edebilecek makine öğrenmesi modelleri geliştirilebilir.

\section{Kaynakça}

Agrawal, G. (2017). Should India Stay Away from the Fourth Revolution?. Available at SSRN 3084256. https://doi.org/10.2139/ssrn.3084256

Angelopoulos, A., Michailidis, E. T., Nomikos, N., Trakadas, P., Hatziefremidis, A., Voliotis, S., \& Zahariadis, T. (2020). Tackling faults in the industry 4.0 era-a survey of machinelearning solutions and key aspects. Sensors, 20(1), 109. https://doi.org/10.3390/s20010109

Ayvaz, S., \& Alpay, K. (2021). Predictive maintenance system for production lines in manufacturing: A machine learning approach using IoT data in real-time. Expert Systems with Applications, 173, 114598. https://doi.org/10.1016/j.eswa.2021.114598
Bektaş, O. Ğ. U. Z. (2020). Kestirimci Bakım İçin Döner Mekanizma Bozulma Eğrisinin Tanımlanması. Avrupa Bilim ve Teknoloji Dergisi, (19), 420-428. https://doi.org/10.31590/ejosat.708257

Calayır, G. N., \& Kabak, M. (2021). Bakım için makine ögrenme tekniklerinin analizi ve bir uygulama. Journal of Turkish Operations Management, 5(1), 662-675.

Carvalho, T. P., Soares, F. A., Vita, R., Francisco, R. D. P., Basto, J. P., \& Alcalá, S. G. (2019). A systematic literature review of machine learning methods applied to predictive maintenance. Computers \& Industrial Engineering, 137, 106024. https://doi.org/10.1016/j.cie.2019.106024

Cavalieri, S., \& Cutuli, G. (2010, September). Performance evaluation of OPC UA. In 2010 IEEE 15th conference on emerging technologies \& factory automation (ETFA 2010) (pp. 1-8). https://doi.org/10.1109/ETFA.2010.5641184

Chazhoor, A., Mounika, Y., Sarobin, M. V. R., Sanjana, M. V., \& Yasashvini, R. (2020, October). Predictive Maintenance using Machine Learning Based Classification Models. In IOP Conference Series: Materials Science and Engineering (Vol. 954, No. 1, p. 012001). IOP Publishing. https://doi.org/10.1088/1757-899X/954/1/012001

Çınar, Z. M., Abdussalam Nuhu, A., Zeeshan, Q., Korhan, O., Asmael, M., \& Safaei, B. (2020). Machine learning in predictive maintenance towards sustainable smart manufacturing in industry 4.0. Sustainability, 12(19), 8211. https://doi.org/10.3390/su12198211

Gedikli, T., ERVURAL, B. Ç., \& ŞEN, D. T. (2021). Bulanık TOPSIS ve Bulanık AHP Yaklaşımlarıyla En Uygun Bakım Stratejisinin Belirlenmesi: Bir Gıda İşletmesinde Uygulama. Avrupa Bilim ve Teknoloji Dergisi, (22), 212-225. https://doi.org/10.31590/ejosat.838168

Kimera, D., \& Nangolo, F. N. (2020). Predictive maintenance for ballast pumps on ship repair yards via machine learning. Transportation Engineering, 2, 100020. https://doi.org/10.1016/j.treng.2020.100020

Lauro, C. N., \& Palumbo, F. (2000). Principal component analysis of interval data: a symbolic data analysis approach. $\begin{array}{lll}\text { Computational } \quad \text { statistics, } & \text { 15(1), }\end{array}$ https://doi.org/10.1007/s001800050038

Lei, Y., Li, N., Gontarz, S., Lin, J., Radkowski, S., \& Dybala, J. (2016). A model-based method for remaining useful life prediction of machinery. IEEE Transactions on reliability, 65(3),

1314-1326. https://doi.org/10.1109/TR.2016.2570568.

Martins, J. P. S., Rodrigues, F. M., \& Henriques, N. (2020). Modeling system based on machine learning approaches for predictive maintenance applications. KnE Engineering, 2020, 857-871. https://doi.org/10.18502/keg.v5i6.7105

Masani, K. I., Oza, P., \& Agrawal, S. (2019). Predictive maintenance and monitoring of industrial machine using machine learning. Scalable Computing: Practice and Experience, 20(4), 663-668. https://doi.org/10.12694/scpe.v20i4.1585 
Oktar, Ş. (2014). Demiryollarında araç bakım ve onarımı. Demiryolu Mühendisliği, (1), 38-40.

Özgür-Ünlüakın, D., Türkali, B., Karacaörenli, A., \& Aksezer, S. Ç. (2019). A DBN based reactive maintenance model for a complex system in thermal power plants. Reliability Engineering \& System Safety, 190, 106505. https://doi.org/10.1016/j.ress.2019.106505

Özkat, E. C. (2021). Makine Öğrenmesi Metodolojisi Kullanılarak Yüksek Hızlı Rulmanlarda Sağlık Göstergesinin Belirlenmesi. Avrupa Bilim ve Teknoloji Dergisi, (22), 176-183. https://doi.org/10.31590/ejosat.869285

Sirvio, K. M. (2015). Intelligent Systems in Maintenance Planning and Management. In Intelligent Techniques in Engineering Management (pp. 221-245). Springer, Cham. https://doi.org/10.1007/978-3-319-17906-3_10

Tahan, M., Tsoutsanis, E., Muhammad, M., \& Karim, Z. A. (2017). Performance-based health monitoring, diagnostics and prognostics for condition-based maintenance of gas turbines: A review. Applied energy, 198, 122-144. https://doi.org/10.1016/j.apenergy.2017.04.048

Tessaro, I., Mariani, V. C., \& Coelho, L. D. S. (2020). Machine Learning Models Applied to Predictive Maintenance in Automotive Engine Components. In Multidisciplinary Digital Publishing Institute Proceedings (Vol. 64, No. 1, p. 26). https://doi.org/10.3390/IeCAT2020-08508

Turker, B. B., Yemez, Y., Sezgin, T. M., \& Erzin, E. (2017). Audio-facial laughter detection in naturalistic dyadic conversations. IEEE Transactions on Affective Computing, $8(4)$, 534-545. https://doi.org/10.1109/TAFFC.2017.2754256.

Wang, Q., Bu, S., \& He, Z. (2020). Achieving predictive and proactive maintenance for high-speed railway power equipment with LSTM-RNN. IEEE Transactions on Industrial Informatics, 16(10), 6509-6517. https://doi.org/10.1109/TII.2020.2966033

Yeşilkanat, C. M. (2020). Spatio-temporal estimation of the daily cases of COVID-19 in worldwide using random forest machine learning algorithm. Chaos, Solitons \& Fractals, 140, 110210. https://doi.org/10.1016/j.chaos.2020.110210

Zonta, T., da Costa, C. A., da Rosa Righi, R., de Lima, M. J., da Trindade, E. S., \& Li, G. P. (2020). Predictive maintenance in the Industry 4.0: A systematic literature review. Computers \&Industrial Engineering, 106889.

https://doi.org/10.1016/j.cie.2020.106889 